\title{
Low-protein diet in puberty impairs testosterone output and energy metabolism in male rats
}

\author{
Júlio Cezar de Oliveira1,2,3, Egberto Gaspar de Moura², Rosiane Aparecida Miranda1,4, \\ Ana Maria Praxedes de Moraes', Luiz Felipe Barella1, Ellen Paula Santos da Conceição², Rodrigo Mello Gomes5, \\ Tatiane Aparecida Ribeiro', Ananda Malta1, Isabela Peixoto Martins', Claudinéia Conationi da Silva Franco1, \\ Patrícia Cristina Lisboa ${ }^{2, *}$ and Paulo Cezar de Freitas Mathias',* \\ ${ }^{1}$ Laboratório de Biologia Celular da Secreção, Departamento de Biotecnologia, Genética e Biologia Celular, Universidade Estadual de Maringá, \\ Maringá, Brazil \\ 2Departamento de Ciências Fisiológicas, Laboratório de Fisiologia Endócrina, Instituto de Biologia Roberto Alcântara Gomes, Universidade do Estado do \\ Rio de Janeiro, Rio de Janeiro, Brazil \\ IInstituto de Ciências da Saúde, Universidade Federal de Mato Grosso, Sinop, Brazil \\ ${ }^{4}$ Instituto de Biofísica Carlos Chagas Filho, Universidade Federal do Rio de Janeiro, Rio de Janeiro, Brazil \\ ${ }^{5}$ Departamento de Ciências Fisiológicas, Universidade Federal de Goiás, Goiânia, Brazil
}

Correspondence should be addressed to J C de Oliveira: biojborges@gmail.com

*(P C Lisboa and P C de Freitas Mathias contributed equally to this work)

\section{Abstract}

We examined the long-term effects of protein restriction during puberty on the function of hypothalamic-pituitary-adrenal (HPA) and hypothalamic-pituitary-gonadal (HPG) axes in male rats. Male Wistar rats from the age of 30 to 60 days were fed a low-protein $\operatorname{diet}(4 \%, \mathrm{LP})$. A normal-protein diet $(20.5 \%)$ was reintroduced to rats from the age of 60 to 120 days. Control rats were fed a normal-protein diet throughout life (NP). Rats of 60 or 120 days old were killed. Food consumption, body weight, visceral fat deposits, lipid profile, glycemia, insulinemia, corticosteronemia, adrenocorticotropic hormone $(\mathrm{ACTH})$, testosteronemia and leptinemia were evaluated. Glucose-insulin homeostasis, pancreatic-islet insulinotropic response, testosterone production and hypothalamic protein expression of the androgen receptor (AR), glucocorticoid receptor (GR) and leptin signaling pathway were also determined. LP rats were hypophagic, leaner, hypoglycemic, hypoinsulinemic and hypoleptinemic at the age of 60 days $(P<0.05)$. These rats exhibited hyperactivity of the HPA axis, hypoactivity of the HPG axis and a weak insulinotropic response $(P<0.01)$. LP rats at the age of 120 days were hyperphagic and exhibited higher visceral fat accumulation, hyperleptinemia and dyslipidemia; lower blood ACTH, testosterone and testosterone release; and reduced hypothalamic expression of AR, GR and SOCS3, with a higher pSTAT3/STAT3 ratio $(P<0.05)$. Glucoseinsulin homeostasis was disrupted and associated with hyperglycemia, hyperinsulinemia and increased insulinotropic response of the pancreatic islets. The cholinergic and glucose pancreatic-islet responses were small in 60-day-old LP rats but increased in 120-day-old LP rats. The hyperactivity of the HPA axis and the suppression of the HPG axis caused by protein restriction at puberty contributed to energy and metabolic disorders as long-term consequences.

\section{Key Words}

- metabolic programming

- insulin resistance

- insulinotropic

- pancreatic islets

- hypothalamic-pituitarygonadal axis
Journal of Endocrinology (2018) 237, 243-254 


\section{Introduction}

Insulin resistance and obesity are complex metabolic disorders that exhibit several etiologies. Metabolic disorders in adult life are associated with disturbances in neuroendocrine pathways that are malprogrammed during critical stages of life (Ravelli et al. 1999, de Oliveira et al. 2013). The worldwide pandemic of obesity and type 2 diabetes mellitus (T2DM), especially in developing countries, is associated with caloric energy restriction during critical stages of development (Barker 2004, Uauy et al. 2011); this restriction contributes to metabolic syndrome.

Hyperactivity of the hypothalamic-pituitaryadrenal (HPA) axis (Wang 2005) and hypoactivity of the hypothalamic-pituitary-gonadal (HPG) axis (MauvaisJarvis 2011) contribute to metabolic disturbances and lead to insulin resistance, T2DM and obesity. In males, testosterone deficiency may promote insulin resistance and increase the risk of T2DM (Kapoor et al. 2005, Grossmann et al. 2010) and visceral obesity (Jones 2010b, Hamilton et al. 2011). Cortisol/corticosterone excess also contributes to insulin resistance and visceral obesity (de Guia \& Herzig 2015). A maternal low-protein diet is also associated with hypotestosteronemia (Chamson-Reig et al. 2009) and hypercorticosteronemia (Reyes-Castro et al. 2012) in offspring, which link these hormone alterations with nutritional disturbances in critical stages of life.

Protein restriction during (de Oliveira et al. 2013) or just after puberty (Malta et al. 2014) malprograms rats to exhibit higher visceral fat depots, insulin secretion and inappropriate autonomic nervous system responses in adulthood. Indeed, young adolescent women exposed to moderate or severe malnutrition during the Dutch famine episode in 1944-1945 exhibited high T2DM risk in adulthood (van Abeelen et al. 2012). Together, these data emphasize that metabolisms of both animals and human are vulnerable to protein-calorie restriction during puberty, leading to long-term consequences. Rising levels of gonadal steroid hormones during puberty program the sensitivity of the adult HPA axis to gonadal steroids in adulthood (Evuarherhe et al. 2009). Notably, a reciprocal interaction between these endocrine systems is evident. Sex steroid hormone output and HPG function are inhibited during stress conditions, and HPA function depends on gonadal-adrenal interaction in the paraventricular nucleus of the hypothalamus (Viau 2002, Retana-Marquez et al. 2003).

The present study hypothesized that protein restriction during puberty would negatively affect male rat testosterone production, which is associated with dysfunction in the HPA axis and may malprogram body composition and glucose homeostasis in adulthood. Therefore, we aimed to assess HPA and HPG axis markers, including body composition, the hypothalamus-leptin signaling pathway, lipid profile and function of the pancreatic islets, in rats fed a low-protein diet throughout puberty followed by a period of dietary reestablishment. We thus aimed to elucidate reciprocal interactions between the HPA and HPG neuroendocrine systems involved in metabolic syndrome later in life.

\section{Materials and methods}

\section{Diet treatment and animal groups}

The Ethical Committee for Animal Experiments of the State University of Maringá, which adheres to Brazilian Federal Law, approved this protocol. Rats were maintained in groups of 5 per cage under controlled conditions (temperature: $22 \pm 2^{\circ} \mathrm{C}$; photoperiod: 07:00-19:00 h; and water and food ad libitum) throughout the protocol.

Male Wistar rats aged 30 days were randomly assigned to two different groups ( $n=40$ rats per group). Control rats were fed a normal-protein diet ad libitum (20.5\% protein, Nuvital, Curitiba/PR, Brazil) throughout the experimental protocol (normal-protein group, NP), and the proteinrestricted rats (low-protein group, LP) received an isocaloric low-protein diet ( $4 \%$ protein) from the age of 30 to 60 days. Diets were composed as previously described (Malta et al. 2016) and as shown in Table 1. The salt and vitamin mixture used in the manufactured diet follows AIN-93 recommendations (Reeves et al. 1993).

Table 1 Composition of the low- and normal-protein diets.

\begin{tabular}{|c|c|c|c|c|}
\hline \multirow[b]{2}{*}{ Diet components } & \multicolumn{2}{|c|}{$\begin{array}{c}\text { Normal protein } \\
(20.5 \%)\end{array}$} & \multicolumn{2}{|c|}{$\begin{array}{c}\text { Low protein } \\
(4.0 \%)\end{array}$} \\
\hline & $(\mathrm{g} / \mathrm{kg})$ & $(\mathrm{kJ} / \mathrm{kg})$ & $(g / k g)$ & $(\mathrm{kJ} / \mathrm{kg})$ \\
\hline Sucrose & 127.2 & 2.129 & 200.0 & 3.347 \\
\hline Cornstarch & 527.5 & 8.828 & 642.5 & 10.753 \\
\hline Casein (88\% protein) & 233.3 & 3.905 & 45.5 & 0.761 \\
\hline Mix of mineral salts* & 32.0 & - & 32.0 & - \\
\hline Mix of vitamins* & 16.0 & - & 16.0 & - \\
\hline Soybean oil & 48.0 & 1.807 & 48.0 & 1.807 \\
\hline Fish oil & 16.0 & 0.602 & 16.0 & 0.602 \\
\hline Total & 1000.0 & 17.272 & 1000.0 & 17.272 \\
\hline
\end{tabular}

The dietary component values are presented as $\mathrm{g} / \mathrm{kg}$ of diet and the energy in $\mathrm{kJ} / \mathrm{kg}$.

*The salt and vitamin mixture used in the manufactured diet followed the AIN-93 recommendation (Reeves et al. 1993). 
One batch of rats $(n=20)$, sampled equally from both groups, was killed at the age of 60 days and the other $(n=20)$ at the age of 120 days to investigate long-term effects of protein restriction. Tissues and blood samples were collected, and body length and the Lee index were evaluated (Bernardis \& Patterson 1968).

\section{Food consumption and body weight assessment}

Food consumption and body weight were assessed every two days throughout the experiment. Absolute food intake was calculated as the difference between the total food administered two days before $\left(\mathrm{D}_{\text {initial }}\right)$ and the amount of food remaining $\left(\mathrm{D}_{\text {final }}\right)$, divided by the number of days and the number of rats per cage: $\left(\mathrm{FI}_{(\mathrm{g})}=\left(\mathrm{D}_{\text {initial }}-\mathrm{D}_{\text {final }}\right) / 2 / 5\right)$ (Vicente et al. 2004, de Oliveira et al. 2011). Spilled food was measured, but it was not significant compared to the amount consumed. Relative food intake was calculated as the value of absolute food intake divided by the mean body weight of the 5 rats in each cage. Daily body weight gain was calculated as the subtraction of each body weight value from the body weight value on the prior day, from 30 until 120 days of age.

\section{Intravenous glucose tolerance test (ivGTT)}

Rats were anesthetized with a ketamine and xylazine mix ( 3 and $0.6 \mathrm{mg} / 100 \mathrm{~g}$ of body weight, respectively) at the age of 60 or 120 days and were subjected to a surgical procedure to implant a silicone cannula into the right jugular vein. An ivGTT was performed after a 12-h fast (19:00-07:00 h) in conscious rats $(n=10)$, as previously described (de Oliveira et al. 2011). Glycemia was measured using the glucose oxidase method (Trinder 1969) with a commercial kit (Gold Analisa; Belo Horizonte/MG, Brazil). Insulinemia was measured by the radioimmunoassay (RIA) method (Scott et al. 1981) in a Wizard2 Automatic Gamma Counter (PerkinElmer) with 125I-labeled recombinant human insulin (PerkinElmer). The intra- and inter-assay coefficients of variation for insulin detection were 9.8 and $12.2 \%$, respectively, and the insulin level detection limit was $1.03 \mathrm{pmol} / \mathrm{L}$.

Insulinemia and glycemia values at baseline and following ivGTT were used to calculate the insulin sensitivity index (ISI), which generates a reasonable approximation of whole-body insulin sensitivity. ISI was calculated as follows: ISI $=10^{4} / \sqrt{ }($ fasting glycemia $\times$ fasting insulinemia $) \times\left(\mathrm{AUC} \Delta_{\text {Glycemia }} \times \mathrm{AUC} \Delta_{\text {Insulinemia }}\right)$ (Matsuda \& DeFronzo 1999).

\section{Pancreatic islet isolation and insulin secretion}

Pancreatic islets from 60- and/or 120-day-old rats ( $n=6$ per group) were isolated using the collagenase technique. Insulin secretion stimulation was adapted to a baseline glucose concentration and stimulated with different glucose concentrations, as previously described (de Oliveira et al. 2013, Malta et al. 2016). Islets from another group of rats ( $n=6$ per group) were incubated for $60 \mathrm{~min}$ in Krebs-Ringer solution containing stimulatory acetylcholine concentrations $((\mu \mathrm{mol} / \mathrm{L}): 0.1 ; 1.0 ; 10.0$; 100.0 and 1000.0) in the presence of $8.3 \mathrm{mmol} / \mathrm{L}$ glucose and $10 \mu \mathrm{mol} / \mathrm{L}$ neostigmine to avoid acetylcholinesterase action. Supernatants from the incubations were collected to examine cholinergic muscarinic function and were stored at $-20.0^{\circ} \mathrm{C}$ for further insulin quantification using RIA (Scott et al. 1981).

Insulin is expressed as $\mathrm{pmol} / \mathrm{L}$ for every 4 isolated pancreatic islets.

\section{Testosterone production}

Testosterone production was assessed from the right testicles of 60- and/or 120-day-old rats ( $n=6$ per group). Testicles were decapsulated and sliced into four pieces weighing approximately $75 \mathrm{mg}$. The slices were incubated with or without $100 \mathrm{IU} / \mathrm{mL}$ human chorionic gonadotrophin (hCG; Sigma-Aldrich) for $90 \mathrm{~min}$ in $1.5 \mathrm{~mL}$ of oxygenated Gibco Cell Culture Medium M199 (Life Technologies) at $34^{\circ} \mathrm{C}$ (Noriega et al. 2009). Samples were centrifuged at $3000 \mathrm{~g}$ for $5 \mathrm{~min}$ at $4^{\circ} \mathrm{C}$, and the supernatant $(1000 \mu \mathrm{L})$ was collected and stored at $-80^{\circ} \mathrm{C}$ for subsequent quantification of testosterone release using an enzyme-linked immunosorbent assay (ELISA) kit (Enzo Life Sciences, Plymouth Meeting, PA, USA). Testosterone is expressed as $\mathrm{pmol} / \mathrm{L}$ per gram of testicle tissue.

\section{Fat store assessment}

Rats were killed at the end of all experimental procedures, and retroperitoneal and mesenteric fat pad stores were removed and weighed to evaluate body composition.

\section{Western blotting}

The expression of leptin receptor (ObR-b), the signal transducer and activator of transcription 3 (STAT3), phosphorylated-STAT3 (pSTAT3), Janus kinase 2 (JAK2), phosphorylated-JAK2 (pJAK2), the suppressor of cytokine 
signaling 3 (SOCS3), androgen receptor (AR) and glucocorticoid receptor (GR) proteins in hypothalamus homogenates obtained from 60- and 120-day-old rats $(n=6)$ were measured using Western blotting, as previously described (Miranda et al. 2017).

The following primary antibodies (Santa Cruz Biotechnology) were used: anti-ObR-b, anti-JAK2, antipJAK2, anti-STAT3, anti-pSTAT3 and anti-SOCS3 (all at $1: 500$ ) and anti-AR, anti-GR and anti- $\beta$-actin (all at 1:1000). Polyvinylidene difluoride filters were washed three times with $0.1 \%$ Tween-TBS, followed by a 60 -min incubation with appropriate secondary antibodies conjugated to biotin (Santa Cruz Biotechnology). Membranes were incubated with streptavidin conjugated with horseradish peroxidase (HRP) (Caltag Laboratories, Burlingame, CA, USA). Immunoreactive proteins were visualized using an enhanced chemiluminescence (ECL) prime kit and Image Quant LAS (GE Healthcare). Protein bands were quantified using densitometry in ImageJ 1.4 (Wayne Rasband, National Institutes of Health, Bethesda, MD, USA). $\beta$-actin protein content (Santa Cruz Biotechnology, diluted 1:1000 in TTBS) was used for normalization. Representative Western blotting images were obtained from the same membranes.

Lipid profile and leptin, corticosterone, adrenocorticotrophic hormone and

\section{testosterone plasma level measurements}

Total blood samples were collected from 12-h fasted (20:0008:00h) 60- and 120-day-old rats $(n=10)$, centrifuged and maintained at $-80^{\circ} \mathrm{C}$ to assess lipid profile and hormone levels.

Plasma levels of triglycerides, total cholesterol and high-density lipoprotein (HDL)-cholesterol were assessed using a colorimetric method and commercial kits (Gold Analisa; Belo Horizonte, MG, Brazil). Circulating very lowdensity lipoprotein (VLDL)- and low-density lipoprotein (LDL)-cholesterol levels were quantified using the Friedewald calculation: VLDL-cholesterol = triglycerides $/ 5$ and LDL-cholesterol = total cholesterol - (HDL-cholesterol + VLDL-cholesterol), respectively.

The Castelli index, which predicts the atherogenic index associated with lipid profile, assesses the risk for development of atherogenesis and coronary artery disease (Criqui \& Golomb 1998, Olamoyegun et al. 2016). The following established formula was used to calculate atherogenic indexes: Castelli index I=total cholesterol/ HDL-cholesterol, and Castelli index II=LDL-cholesterol/ HDL-cholesterol.
A commercial ELISA kit was used to quantify plasma levels of leptin, corticosterone, testosterone (Enzo Life Sciences) and adrenocorticotrophic hormone (ACTH) (MyBioSource, San Diego, CA, USA). The intra- and inter-assay coefficients of variation were $5.9 \%$ and $7.2 \%$, respectively, for leptin, $7.7 \%$ and $9.7 \%$ for corticosterone, $9.5 \%$ and $11.7 \%$ for testosterone, and $3.7 \%$ and $4.7 \%$ for ACTH. Hormone level detection limits were (in pmol/L) 4.20 for leptin, 74.46 for corticosterone, 1967.49 for testosterone and 0.22 for ACTH.

\section{Statistical analyses}

Data are shown as the means \pm S.E.M., and results were subjected to Student's t-tests or one-way ANOVAs when appropriate. Theassociation between plasma corticosterone and plasma testosterone levels was calculated using Pearson's correlation and linear regression analyses. Values of $P$ less than 0.05 were considered statistically significant. Tests were performed using GraphPad Prism version 6.0 for Windows (GraphPad Software).

\section{Results}

\section{Biometric and fasting biochemical and} hormonal parameters

LP rats at the age of 60 days were leaner than NP rats and exhibited decreased body weight $(-72.2 \%, P<0.001)$, body length $(-30.6 \%, P<0.001)$ and mesenteric $(-39.3 \%$, $P<0.01)$ and retroperitoneal fat pads $(-68.0 \%, P<0.001$, Table 2). LP rats at the age of 120 days exhibited a different phenotype, with only a slight reduction in body weight $(-3.4 \%, P>0.05)$ and body length compared to NP rats $(-1.8 \%, P<0.01)$, and higher mesenteric $(+19.8 \%, P<0.01)$ and retroperitoneal fat pads $(+29.1 \% ; P<0.001$, Table 2$)$.

The body weight gain of LP rats was reduced by $87.7 \%$ over the protein restriction period $(P<0.001$, inset of Fig. 1A), and food intake decreased $30.7 \%(P<0.001$, inset of Fig. 1B) compared to NP rats. Notably, body weight gain $(+94.1 \%, P<0.001$, inset of Fig. $1 \mathrm{~A})$ and food intake $(+29.7 \%$; $P<0.001$, inset of Fig. 1B) in LP rats reverted throughout the period of dietary reestablishment.

LP rats at the age of 60 days were hypoglycemic (-27.9\%, $\quad P<0.01), \quad$ hypoinsulinemic $\quad(-46.7 \%$, $P<0.05)$, hypoleptinemic $(-81.6 \%, \quad P<0.01)$ and hypotestosteronemic $(-10.8 \%, P<0.05)$; additionally, they exhibited higher levels of corticosterone $(+53.2 \%$, $P<0.01)$ and ACTH $(+57.4 \% ; P<0.01$, Table 2$)$. The ISI 
Table 2 The effects of protein-calorie restriction during adolescence on biometric and biochemical parameters as short- (60 days old) and long-term (120 days old) consequences in male rats.

\begin{tabular}{|c|c|}
\hline & 60 days old \\
\hline Biometric and biochemical parameters & NP \\
\hline Body weight (g) & $267.20 \pm 7.69$ \\
\hline Body length $(\mathrm{cm})$ & $19.97 \pm 0.15$ \\
\hline Mesenteric fat pad (g/100 g bw) & $0.61 \pm 0.06$ \\
\hline Retroperitoneal fat pad ( $\mathrm{g} / 100 \mathrm{~g} \mathrm{bw})$ & $0.78 \pm 0.08$ \\
\hline Glycemia (mmol/L) & $5.95 \pm 0.11$ \\
\hline Insulinemia (pmol/L) & $30.27 \pm 5.96$ \\
\hline ISI & $12.59 \pm 1.20$ \\
\hline Leptinemia (pmol/L) & $37.78 \pm 7.12$ \\
\hline Corticosteronemia $(\mu \mathrm{mol} / \mathrm{L})$ & $1.26 \pm 0.13$ \\
\hline ACTH (pmol/L) & $41.06 \pm 3.96$ \\
\hline Testosteronemia (pmol/L) & $6.57 \pm 0.26$ \\
\hline
\end{tabular}

\begin{tabular}{c}
\hline $\mathbf{1 2 0}$ days old \\
\hline LP \\
\hline $74.30 \pm 3.90 * * *$ \\
$13.85 \pm 0.30 * * *$ \\
$0.37 \pm 0.03 * *$ \\
$0.25 \pm 0.03 * * *$ \\
$4.29 \pm 0.40 * *$ \\
$16.12 \pm 2.78 *$ \\
$30.77 \pm 2.43 * * *$ \\
$6.97 \pm 0.42 * *$ \\
$1.94 \pm 0.08 * *$ \\
$64.64 \pm 8.25 * *$ \\
$5.86 \pm 0.17 *$
\end{tabular}

\begin{tabular}{c}
\hline $\mathbf{6 0}$ days old \\
\hline $\mathrm{NP}$ \\
\hline $403.10 \pm 5.00$ \\
$23.23 \pm 0.11$ \\
$0.81 \pm 0.03$ \\
$1.41 \pm 0.08$ \\
$4.84 \pm 0.12$ \\
$36.27 \pm 5.16$ \\
$10.64 \pm 0.84$ \\
$53.21 \pm 7.30$ \\
$1.68 \pm 0.07$ \\
$62.92 \pm 2.30$ \\
$6.872 \pm 0.28$
\end{tabular}

120 days old
LP
$389.40 \pm 4.76^{\text {ns }}$
$22.82 \pm 0.14^{*}$
$0.97 \pm 0.04^{* *}$
$1.82 \pm 0.07^{* * *}$
$5.41 \pm 0.05^{* *}$
$57.43 \pm 6.12^{*}$
$7.56 \pm 0.60^{* *}$
$109.36 \pm 23.58^{*}$
$1.54 \pm 0.11^{\text {ns }}$
$46.17 \pm 5.56^{* *}$
$5.75 \pm 0.29^{*}$

Data are expressed as the means \pm S.E.M. of rats ( $n=20$ for biometric and $n=10$ for biochemical parameters and ISI calculation) from 4 different litters. Significant differences between NP and LP groups at 60 or 120 days old were compared using Student's $t$ test. $* P<0.05, * * P<0.01$ and $* * * P<0.001$. ns, not significant

was increased in 60-day-old LP rats $(+144.4 \% ; P<0.001$, Table 2). In contrast, 120-day-old LP rats exhibited diminished ISI values $(-28.9 \% ; P<0.01$, Table 2$)$, hyperglycemia $(+10.6 \%, \quad P<0.01)$, hyperinsulinemia $(+58.3 \%, \quad P<0.05)$ and hyperleptinemia (+105.5\%, $P<0.05)$. Corticosteronemia was unaltered $(P=0.329)$, ACTH plasma levels decreased $(-26.6 \%, P<0.01)$ and testosteronemia was reduced $(-16.3 \% ; P<0.05$, Table 2$)$.

Lipid profiles of the rats at the age of 60 and 120 days are provided in Table 3. LP rats at the age of 60 days exhibited reduced triglycerides $(-39.3 \%, \quad P<0.01)$, increased total cholesterol $(+39.8 \%, P<0.01)$, decreased VLDL-cholesterol $(-33.4 \%, P<0.001)$, increased LDLcholesterol $(+125.7 \%, P<0.001)$ and increased HDLcholesterol $(+30.1 \%, P<0.001)$. Castelli indexes I and II increased $10.5 \%$ and $119.6 \%$, respectively, in 60-day-old LP rats $(P<0.01$, Table 3$)$. LP rats at 120 days old exhibited an increase of $+26.8 \%$ for triglycerides, $+15.5 \%$ for total cholesterol, $+30.7 \%$ for VLDL-cholesterol and $+41.4 \%$ for LDL-cholesterol, as well as a reduction of $13.1 \%$ in HDLcholesterol values compared to NP rats $(P<0.05$, Table 3$)$. Castelli indexes I and II increased $+16.2 \%$ and $58.4 \%$, respectively, in 120 -day-old LP rats $(P<0.01$, Table 3$)$.

\section{Glucose-insulin homeostasis}

The 60-day-old LP rats were hypoinsulinemic (-32.0\%; $P<0.05$, inset of Fig. $2 \mathrm{~A})$ and hypoglycemic $(-14.3 \%$; $P<0.05$, inset of Fig. 2B) according to the ivGTT compared to the NP rats. LP rats were hyperinsulinemic $(+36.1 \% ; P<0.05$, inset of Fig. $2 \mathrm{C})$ and exhibited similar glucose levels $(P=0.122$, inset of Fig. 2D) as NP rats at 120 days old.

\footnotetext{
http://joe.endocrinology-journals.org

https://doi.org/10.1530/JOE-17-0606
}

() 2018 Society for Endocrinology Published by Bioscientifica Ltd. Printed in Great Britain

\section{Glucose and/or acetylcholine} insulinotropic response

Increasing concentrations of glucose or acetylcholine increased insulin secretion in a dose-dependent manner in both 60-day-old rat groups (Fig. 3). However, the increment of insulin secretion from islets of LP rats was smaller than that of NP rats under glucose $(P<0.05$, Fig. 3A) and acetylcholine $(P<0.05$, Fig. 3B) stimulation. Conversely, islets from 120-day-old LP rats were more responsive to increasing glucose and acetylcholine concentrations $(P<0.05$, Fig. $3 C$ and D).

\section{Testosterone production/secretion and plasma corticosterone and testosterone correlation}

Testosterone secretion in 60-day-old LP rats was reduced by 73.9\% $(P<0.001$, Fig. 4A). The increment of testosterone production following hCG stimulation was $16.9 \%$ in NP rats and $65.4 \%$ in LP rats $(P<0.001$, Fig. $4 \mathrm{~A})$.

Testosterone release from 120-day-old LP rats exhibited a smaller reduction of $-12.0 \%$ ( $P<0.01$, Fig. $4 \mathrm{~B})$. However, this parameter did not differ for NP rats under hCG stimulation ( $P=0.716$, Fig. 4B). The magnitude of hCG-stimulated testosterone production in adult rats was $+10.7 \%$ in NP rats and $+19.0 \%$ in LP rats compared to production without hCG $(P<0.01$, Fig. 4B).

Corticosteronemia showed a significant negative correlation with testosteronemia for both animal groups aged 60 days, with higher magnitude for LP rats (NP: $r=-0.803, P<0.05$ and LP: $r=-0.971, P<0.001$; Fig. $4 \mathrm{C})$. At the age of 120 days, the blood values of corticosterone displayed a slight significant negative correlation with 


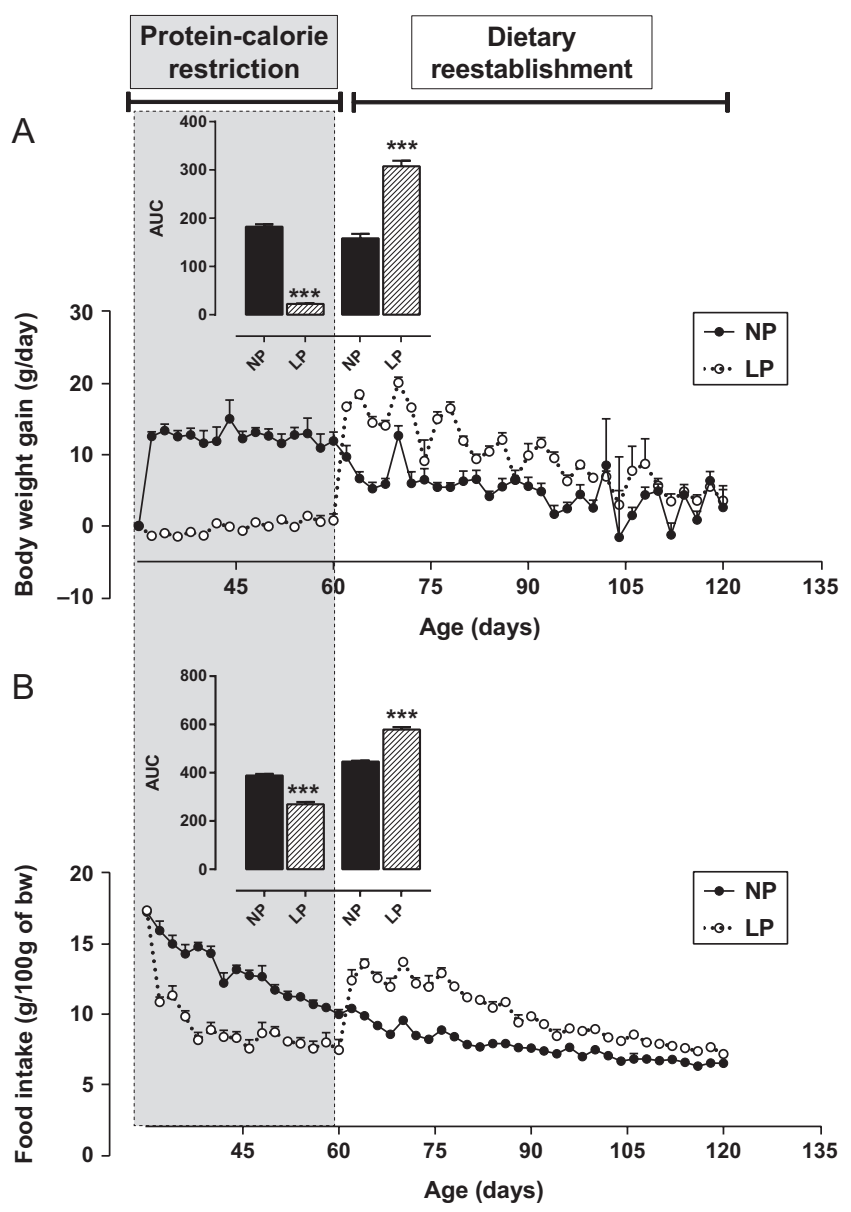

Figure 1

Body weight gain (A) and relative food intake (B). Data are presented as the means \pm S.E.M. of 20 rats from 4 different litters. The left panels, as an inset to each figure, depict the area under the curve (AUC) for both periods of dietary treatment. Bars on the left in each panel depict the $A \cup C$ for body weight gain and relative food intake during the proteincalorie restriction period (30-60 days old). Bars on the right depict the AUC during the period of dietary reestablishment (60-120 days old). $* * * P<0.001$ using Student's $t$ test. testosterone for LP rats $(r=-0.682, P<0.05$; Fig. $4 \mathrm{D})$ but did not for NP rats $(r=0.165, P=0.671$; Fig. 4D).

\section{Hypothalamic androgen and glucocorticoid receptors}

AR protein expression in the hypothalamus was less in 60-day-old LP rats than in NP rats $(-45.8 \% ; P<0.05$, Fig. 5A), and this parameter remained reduced in 120-dayold LP rats $(-25.3 \%, P<0.05$, Fig. 5A). Expression of hypothalamic GR protein decreased by 79.5\% $(P<0.001$, Fig. 5B) in 60-day-old LP rats and $44.3 \%(P<0.05$, Fig. 5B) in 120-day-old LP rats compared to NP rats.

\section{Hypothalamic leptin pathway}

As depicted in the Fig. 6A, pubertal protein restriction did not alter hypothalamic ObR-b protein expression in rats aged $60(P=0.974)$ or 120 days $(P=0.289)$. The pJAK2/JAK2 ratio in hypothalamic tissue was unaltered in rats aged 60 and 120 days $(P>0.05$, Fig. 6B). The pSTAT3/STAT3 ratio was not altered in 60-day-old LP rats $(P=0.443$, Fig. 6C) but increased 3 -fold in 120 -day-old LP rats $(P<0.001$, Fig. 6C). SOCS3 protein expression was decreased by $26.5 \%$ in 60 -day-old LP rats $(P<0.05$, Fig. 6D) and by $49.8 \%$ in 120 -day-old LP rats $(P<0.05$, Fig. $6 \mathrm{D})$.

\section{Discussion}

The current study demonstrated that dysfunction of the HPA axis together with HPG axis impairment due to pubertal malnutrition was associated with physiological changes in adiposity-related signals, leptin and insulin, according to nutritional status. These results support the

Table 3 The effects of protein-calorie restriction during adolescence on the lipid profile as short- (60 days old) and long-term (120 days old) consequences in male rats.

\begin{tabular}{|c|c|c|c|c|}
\hline \multirow[b]{2}{*}{ Lipid profile $(\mu \mathrm{mol} / \mathrm{L})$} & \multicolumn{2}{|c|}{60 days old } & \multicolumn{2}{|c|}{120 days old } \\
\hline & NP & LP & NP & LP \\
\hline Triglycerides & $754.0 \pm 70.7$ & $457.5 \pm 26.6$ ** & $718.1 \pm 27.8$ & $910.4 \pm 46.9 * *$ \\
\hline Total cholesterol & $1831.0 \pm 72.7$ & $2560.0 \pm 150.6 * *$ & $1887.0 \pm 38.9$ & $2180.0 \pm 93.3 *$ \\
\hline VLDL-cholesterol & $317.1 \pm 20.9$ & $211.3 \pm 10.7 * * *$ & $323.1 \pm 10.7$ & $422.4 \pm 15.7 * * *$ \\
\hline LDL-cholesterol & $297.7 \pm 37.3$ & $671.9 \pm 71.5 * *$ & $384.2 \pm 15.2$ & $543.4 \pm 38.8 * *$ \\
\hline HDL-cholesterol & $1281.0 \pm 45.8$ & $1666.0 \pm 58.2 * * *$ & $1388.0 \pm 54.6$ & $1206.0 \pm 58.1 *$ \\
\hline Castelli index I & $1.43 \pm 0.02$ & $1.58 \pm 0.03 * * *$ & $1.54 \pm 0.01$ & $1.79 \pm 0.06 * *$ \\
\hline Castelli index II & $0.22 \pm 0.02$ & $0.49 \pm 0.04 * * *$ & $0.30 \pm 0.02$ & $0.50 \pm 0.05 * *$ \\
\hline
\end{tabular}

Data are expressed as the means \pm S.E.M. of rats $(n=10)$ from 4 different litters. The significant differences between NP and LP groups at the age of 60 or 120 days old were measured using Student's $t$ test.

$* P<0.05, * * P<0.01$ and $* * * P<0.001$.

LP, Low-protein diet-treated group; NP, Normal-protein diet-treated group.

\begin{tabular}{|lr}
\hline http://joe.endocrinology-journals.org & ( 2018 Society for Endocrinology \\
https://doi.org/10.1530/JOE-17-0606 & Published by Bioscientifica Ltd. \\
Printed in Great Britain
\end{tabular}


A
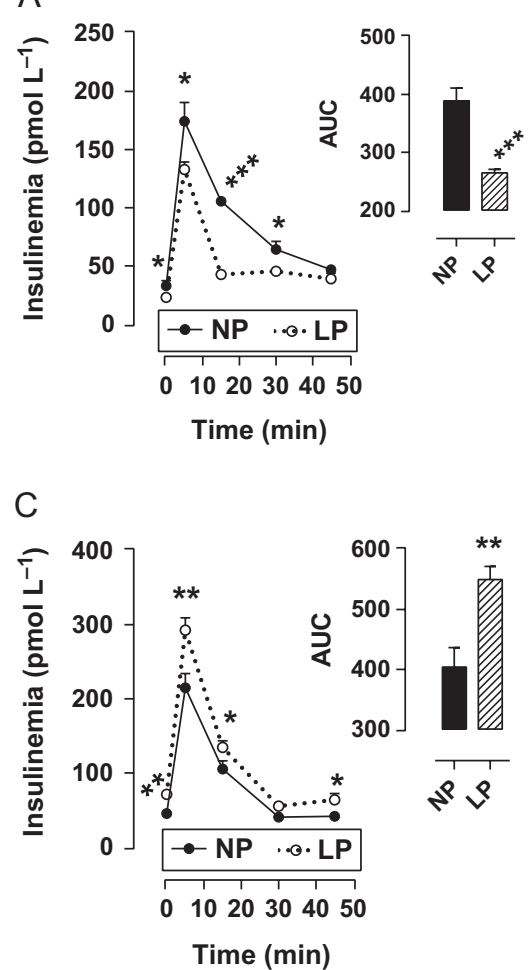
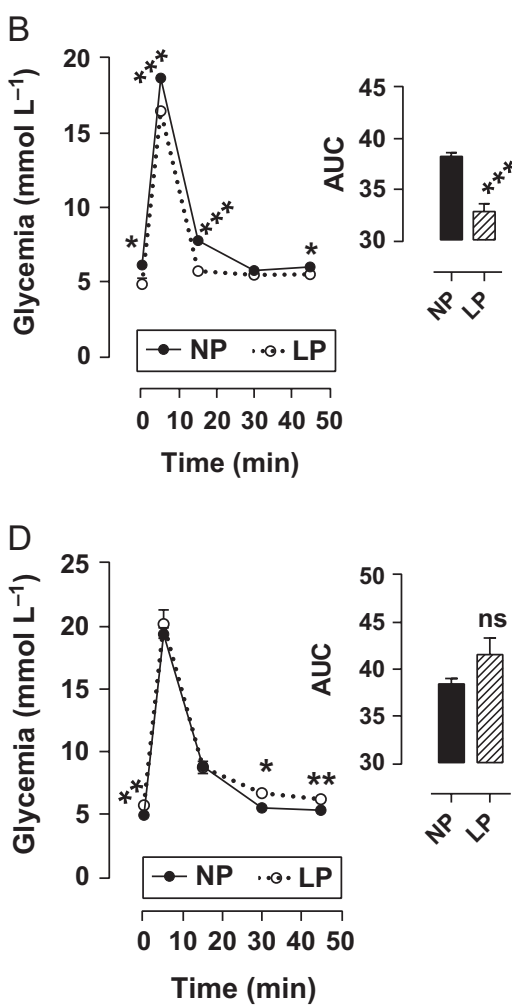

Figure 2

Insulinemia and glycemia during the intravenous glucose tolerance test (ivGTT). Data are presented as the means \pm S.E.M. of 10 rats from 4 different litters. Insulinemia (A) and glycemia (B) during the ivGTT at the end of protein-calorie restriction (60 days old). Insulinemia (C) and glycemia (D) during the ivGTT after the period of dietary reestablishment ( 120 days old). The upper panel of each figure represents the area under the curve (AUC). ${ }^{*} P<0.05, * * P<0.01, * * * P<0.001$ by Student's $t$ test. hypothesis that hyperactivity in the HPA axis, as well as hypoactivity of the HPG axis in puberty, is critical for inducing metabolic dysfunction in males during adulthood (de Oliveira et al. 2013, Malta et al. 2014, 2016). It is likely that human illnesses such as Cushing's syndrome and hypogonadotropic hypogonadism are associated with functional alterations in cortisol, leptin and insulin and that these alterations induce obesity, cardiovascular disease and T2DM (Reynolds et al. 2001, Grumbach 2002, Prodam et al. 2013, Reynolds 2013).

We further speculate that protein restriction during puberty can impair neuroendocrine pathways in the hypothalamus that secondarily may program insulin resistance, dyslipidemia and pancreatic-islet insulinotropic disrupted responses in adult LP rats; however, further experiments are necessary to clarify
A
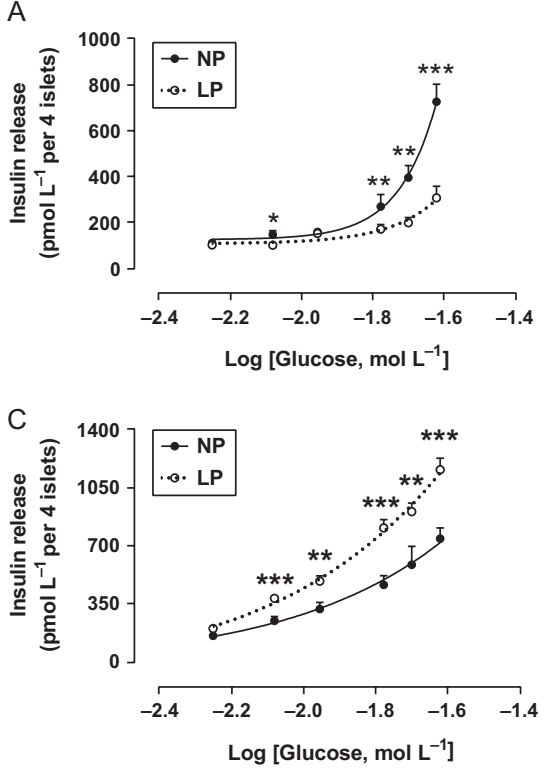

B

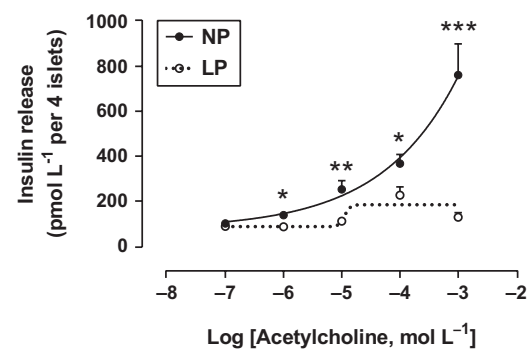

D

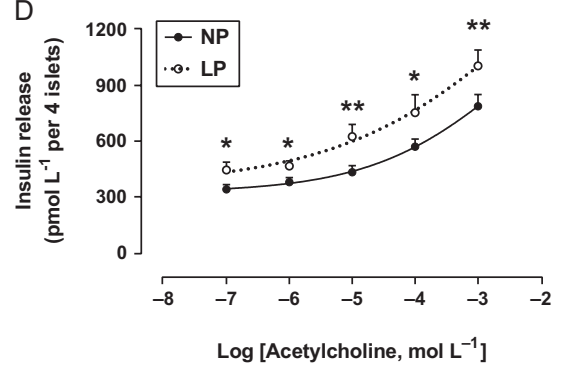

Figure 3

Short- and long-term effects of pubertal protein-calorie restriction on insulin secretion. Data are presented as the means \pm S.E.M. of insulin secretion from the pancreatic islets of 6 rats from 3 different litters. Insulinotropic effect of different glucose ( $A$ and $C$ ) and acetylcholine (B and D) concentrations refers to data obtained from rats at the end of protein-calorie restriction (60 days old) and after dietary reestablishment (120 days old). ${ }^{*} P<0.05, * * P<0.01, * * * P<0.001$ using Student's $t$ test. 
A

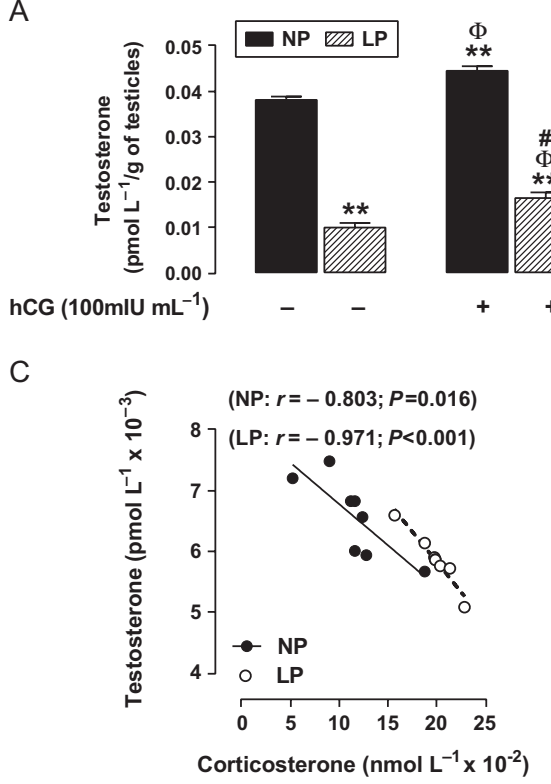

B

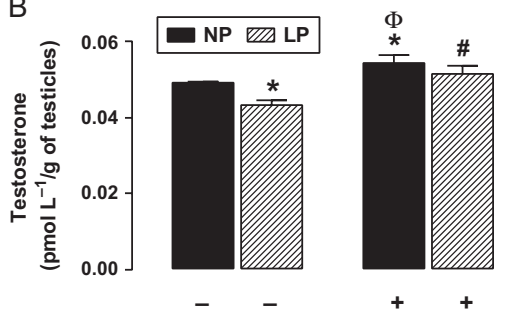

D

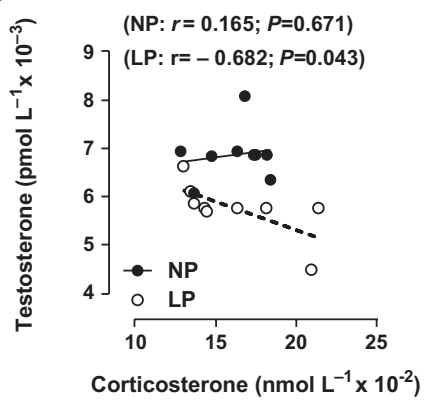

\section{Figure 4}

Short- and long-term effects of pubertal protein-calorie restriction on testosterone output and the correlation between corticosteronemia and testosteronemia. Data are presented as the means \pm S.E.M. of testosterone output for isolated testicles of 6 rats from 3 different litters.

Testosterone output without (-) and with (+) hCG $100 \mathrm{IU} / \mathrm{mL}$ at the end of protein-calorie restriction ( 60 days old, $A$ ) and after the dietary reestablishment (120 days old, B). Correlation between plasma levels of corticosterone and testosterone in rats of 60 days old (C) and those of 120 days old (D). Symbols over the bars depict significant differences between NP and LP values of testosterone output with and without hCG, as determined using a one-way ANOVA, in which ${ }^{*} P<0.01,{ }^{*} * P<0.001$ compared to NP without hCG; ${ }^{\oplus} P<0.001$ compared to LP without hCG; and $\# P<0.001$ compared to NP with hCG. this possibility. Pancreatic islets from 60-day-old LP rats exhibited impaired insulin secretion during glucose and acetylcholine stimulation, leading to a low insulinotropic-cholinergic response at this age. In contrast, dietary reestablishment reverted it to pancreaticislet over function in 120-day-old LP rats, which suggests a greater responsiveness to glucose and cholinergic signaling. Hyperactivity of the parasympathetic tonus in this rat model during adulthood is associated with insulin resistance and obesity (de Oliveira et al. 2013), and it modulates pancreatic function as a compensatory response for the high metabolic demand, which increases the risk of T2DM onset. In addition, an LP diet decreases vagal tonus as a direct effect (Leon-Quinto et al. 1998) and as an indirect and long-term consequence (de Oliveira et al. 2011); this decrease is associated with pancreatic beta-cell dysfunction.

The role of corticosterone in the HPG axis under stress conditions inhibits reproductive function (Viau 2002). This interaction is strongly associated with the regulation of energy homeostasis, especially during puberty (Gomez \& Dallman 2001). Circulating corticosteroid levels decrease the pituitary response to gonadotrophin-releasing hormone $(\mathrm{GnRH})$, which reduces luteinizing hormone (LH) release and negatively affects gonadal hormone production (Tilbrook et al. 2000, Viau 2002). Sixty-day-old LP rats exhibited higher blood levels of corticosterone and ACTH, which were associated with lower testosteronemia and testosterone secretion. Therefore, protein restriction during puberty seems to exert an inhibitory effect on the HPG axis that can be mediated through hyperactivity of the HPA axis. Notably, testosterone production in LP rats at the end of protein restriction was reduced and remained reduced and lower in magnitude in 120-dayold rats after dietary reestablishment, even with hCG in the media. The magnitude of hCG-induced testosterone production was 3.9-fold higher in 60-day-old LP rats and 1.8-fold higher in 120-day-old LP rats compared to NP rats. Therefore, we suggest that the testicles of LP rats exhibited a normal response to gonadotropins, and these changes occur in the hypothalamus or pituitary. One limitation of our study was that we did not measure plasma LH or hypothalamic GnRH. However, at the age of 60 days, hypercorticosteronemia was inversely correlated with testosteronemia in LP rats; this finding suggests that hyperactivity of the HPA axis at this age causes persistent inhibition of HPG function in LP rats that remains into adulthood. In fact, the strength of this correlation was not observed in adulthood, since ACTH was also lower, and corticosterone was unchanged. HPA activation during the acute stress of protein scarcity is prominent in the malprogramming of metabolism, and a hyperactive HPA axis may decrease HPG function and impair reproductive capacity to preserve energy stores (Gomez \& Dallman 2001).

Leptin, insulin, corticosterone and testosterone were altered in 60-day-old LP rats, which suggests complex cross-talk between these hormones. These hormones affect body mass and energy metabolism and imprint an altered regulatory pattern as a long-term consequence. As previously reported, hypoglycemia induces afferent signals that reach the brainstem, especially 
A
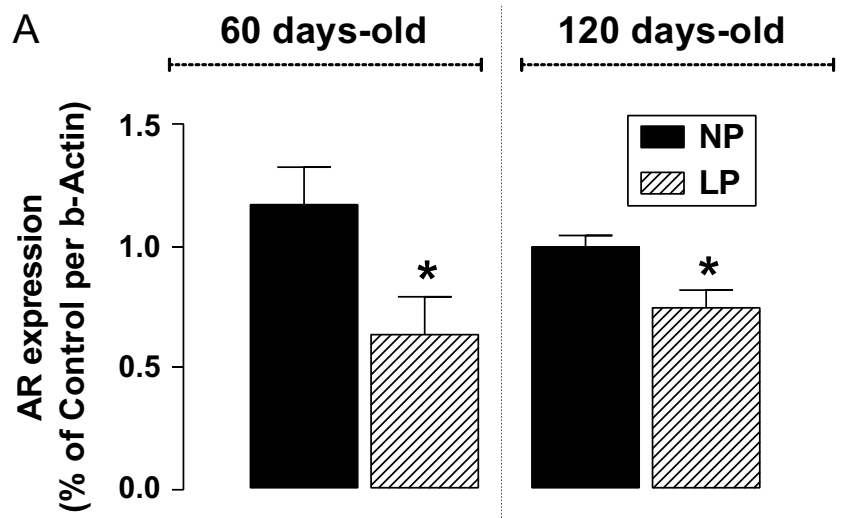

B
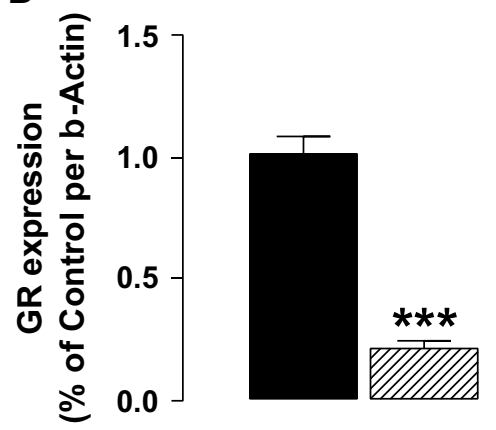

C
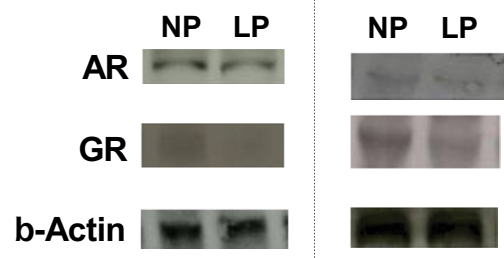

Figure 5

Hypothalamic measurement of $A R(A)$ and GR (B) protein expression. Data are presented as the means \pm S.E.M. of $A R$ and $G R$ protein expression in hypothalamus samples of 6 rats from 3 different litters. Representative blots of AR, GR and $\beta$-actin (control load) are shown in (C). Mean values from the hypothalamic protein expression of AR and GR from LP rats at the end of protein-calorie restriction ( 60 days old) or after dietary reestablishment (120 days old) were significantly different from those in the NP group: ${ }^{*} P<0.01$ and $* * * P<0.001$ using Student's $t$ test.

the nucleus of the tractus solitarius, which activates hypothalamic paraventricular neurons to produce/ secrete corticotrophin-releasing hormone (CRH) and activate the HPA axis (Marty et al. 2007). An inhibitory effect of leptin on CRH and ACTH production/secretion in stress conditions was reported previously (Heiman et al. 1997, Morton et al. 2015). Thus, hyperactivity of the HPA axis in 60-day-old LP rats may be explained by both hypoglycemia and hypoleptinemia. Hyperglycemia and hyperleptinemia were found in 120-day-old LP rats after dietary reestablishment, which also decreased ACTH.
Leptin hypofunction in humans and rodents, which is found in malnutrition, is associated with reduced HPG function (Grumbach 2002). However, even with hyperleptinemia at 120 days of age, those animals had hypotestosteronemia, suggesting a hypothalamic leptin resistance that was not confirmed by evaluation of the leptin signaling pathway in the hypothalamus.

Dyslipidemia, insulin resistance and accumulated higher visceral fat stores in the 120-day-old LP rats may be associated with hypotestosteronemia (Cameron et al. 2016). Castelli indexes I and II were increased, suggesting a high-risk factor for cardiovascular diseases in 120-day-old LP rats. Hypotestosteronemia promotes visceral obesity and insulin resistance in males, and it is a risk factor for cardiovascular diseases associated with T2DM in humans and rodents (Kapoor et al. 2005, Grossmann et al. 2010, Jones $2010 a, b$ ). The physiological role of testosterone on body and energy homeostasis was highlighted in obese men exposed to testosterone therapy (Saad et al. 2016). A lack of testosterone signaling by ARs in adipocytes promotes a metabolic syndrome pattern in mice, with glucose-insulin disruption and susceptibility to high-fat diet-induced visceral obesity (McInnes et al. 2012). High cortisol and LDL-cholesterol levels were also specifically associated with hypertension in obese children and adolescents (Prodam et al. 2013). Alterations in lipid profile may be related to the lower testosterone levels that were observed during the two periods evaluated, because both groups of LP rats were dyslipidemic in rats aged 60 and 120 days.

GR expression in hypothalamus was lower at 60 days of age, probably due to a down-regulatory role of hypercorticosteronemia in these animals, which helps explain why they still exhibited increased ACTH despite higher corticosteronemia. Conversely, if GR was constitutively lower due to protein-calorie restriction, then higher corticosteronemia would have been necessary to suppress ACTH. AR expression in the hypothalamus was decreased due to protein restriction, and lower testosterone production led to a marked decrease in testosterone action. Notably, these receptors remained decreased after dietary reestablishment, despite some recovery. These changes did not sufficiently alter the action of the hormone ligands, except in the case of GR, where the partial recovery may be responsible for the suppression of ACTH and corticosterone normalization.

Leptin and insulin signaling in hypothalamic neuronal circuitry strictly control food intake and energy balance (Schwartz et al. 2000, Woods et al. 2008, Anderson et al. 2016). Changes in the protein expression of leptin signaling in the hypothalamus cannot explain why these 
A

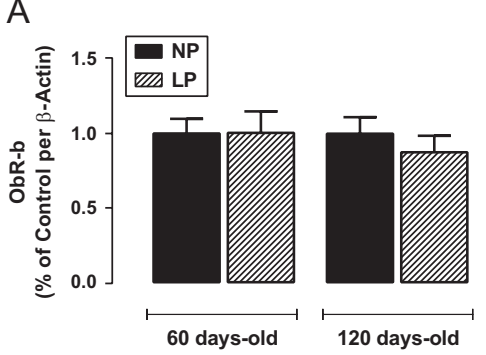

C

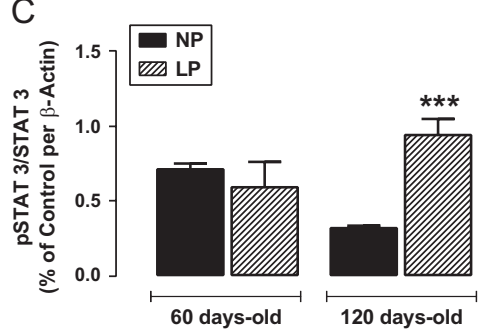

B
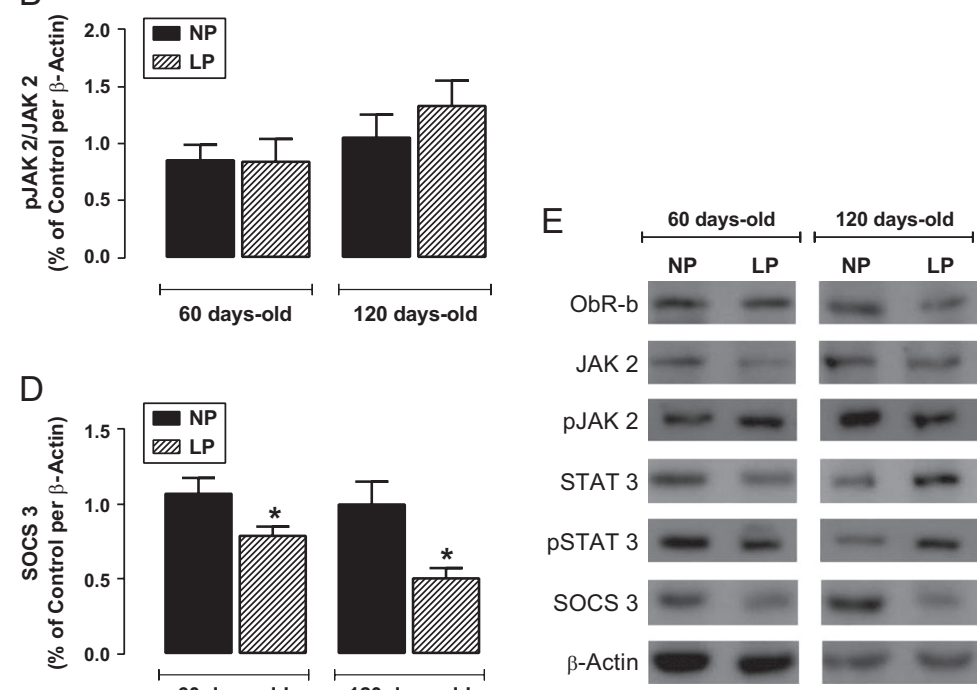

Figure 6

Hypothalamic measurement of protein expression of the leptin signaling pathway. Data are presented as the means \pm S.E.M. of ObR-b (A), pJAK2/JAK2 (B), pSTAT3/STAT3 (C) and SOCS3 (D) protein expression in hypothalamus samples of 6 rats from 3 different litters of each group. Representative blots of ObR-b, pJAK2, JAK2, pSTAT3, STAT3, SOCS3 and $\beta$-actin (control load) are shown in (E). Significant differences between the LP and NP values of hypothalamic protein expression were determined using Student's $t$ test. $* P<0.01$ and $* * * P<0.001$.

animals ate less during protein restriction. LP rats were hyperphagic at dietary reestablishment, because the only alteration observed was lower SOCS3 at both ages and an increase in pSTAT3/STAT3 ratio at 120 days old. Other hormones, such as insulin, also regulate these proteins, and changes in leptinemia did not explain these alterations. Changes other than leptin or insulin may exert direct actions, or other leptin and insulin signaling pathways may promote hyperphagia and/or attenuate catabolic-pathway activation in adult LP rats (Schwartz et al. 2000, Chong et al. 2015).

Leptin regulates the HPG axis and increases testosterone, which regulates leptin synthesis in white adipocytes (Ramos \& Zamoner 2014). We suggest that hypotestosteronemia and hypercorticosteronemia play a critical role in malprogramming, which affects the hypothalamic control of energy homeostasis in adulthood.

Our data support the hypothesis that protein restriction during puberty impairs functional interaction between the HPA and HPG axes and leads to dyslipidemia, visceral fat accumulation, hyperinsulinemia and insulin resistance associated with a disrupted insulinotropic response in the pancreatic islets. These results highlight the fact that persistent neuroendocrine changes imprinted by stress conditions during puberty lead to metabolic syndrome as a long-term consequence in LP rats. These results suggest a risk factor for development of longlasting obesity, cardiovascular diseases and T2DM.

\section{Declaration of interest}

The authors declare that there is no conflict of interest that could be perceived as prejudicing the impartiality of the research reported.

\section{Funding}

This work was funded by the Brazilian Federal Foundation, Conselho Nacional de Desenvolvimento Científico e Tecnológico (CNPq), Coordenação de Aperfeiçoamento de Pessoal de Nível Superior (CAPES), Paraná Science Foundation (Fundação Araucária) and the Carlos Chagas Filho Research Foundation of the State of Rio de Janeiro (Fundação Carlos Chagas Filho de Amparo à Pesquisa do Estado do Rio de Janeiro, FAPERJ).

\section{Author contribution statement}

J C O, P C F M, E G M and P C L conceived and designed the study; J C O, R A $M$ and $L F B$ collected and analyzed data and wrote the manuscript; $A$ M P M, I P M, C C S F, R M G, T A R and A M collected and analyzed data; J C O, R A P and E P S C contributed to Western blot analyses; J C O, P C F M, E G $M, R A M$ and $L F B$ contributed to discussion and reviewed the manuscript. All authors have read and approved the final manuscript.

\section{References}

Anderson EJ, Cakir I, Carrington SJ, Cone RD, Ghamari-Langroudi M, Gillyard T, Gimenez LE \& Litt MJ 201660 years of POMC: regulation of feeding and energy homeostasis by alpha-MSH. Journal of Molecular Endocrinology 56 T157-T174. (https://doi.org/10.1530/JME-16-0014)

Barker DJ 2004 The developmental origins of chronic adult disease. Acta Paediatrica Supplementum 93 26-33. (https://doi. org/10.1111/j.1651-2227.2004.tb00236.x) 
Bernardis LL \& Patterson BD 1968 Correlation between "Lee Index" and carcass fat content in weanling and adults female rats with hypothalamic lesions. Journal of Endocrinology 40 527-528. (https:// doi.org/10.1677/joe.0.0400527)

Cameron JL, Jain R, Rais M, White AE, Beer TM, Kievit P, Winters-Stone K, Messaoudi I \& Varlamov O 2016 Perpetuating effects of androgen deficiency on insulin resistance. International Journal of Obesity $\mathbf{4 0}$ 1856-1863. (https://doi.org/10.1038/ijo.2016.148)

Chamson-Reig A, Thyssen SM, Hill DJ \& Arany E 2009 Exposure of the pregnant rat to low protein diet causes impaired glucose homeostasis in the young adult offspring by different mechanisms in males and females. Experimental Biology and Medicine 234 1425-1436. (https:// doi.org/10.3181/0902-RM-69)

Chong AC, Vogt MC, Hill AS, Bruning JC \& Zeltser LM 2015 Central insulin signaling modulates hypothalamus-pituitary-adrenal axis responsiveness. Molecular Metabolism 4 83-92. (https://doi. org/10.1016/j.molmet.2014.12.001)

Criqui MH \& Golomb BA 1998 Epidemiologic aspects of lipid abnormalities. American Journal of Medicine 105 48S-57S. (https://doi. org/10.1016/S0002-9343(98)00212-5)

de Guia RM \& Herzig S 2015 How do glucocorticoids regulate lipid metabolism? Advances in Experimental Medicine and Biology 872 127-144. (https://doi.org/10.1007/978-1-4939-2895-8_6)

de Oliveira JC, Scomparin DX, Andreazzi AE, Branco RC, Martins AG, Gravena C, Grassiolli S, Rinaldi W, Barbosa FB \& Mathias PC 2011 Metabolic imprinting by maternal protein malnourishment impairs vagal activity in adult rats. Journal of Neuroendocrinology 23 148-157. (https://doi.org/10.1111/j.1365-2826.2010.02095.x)

de Oliveira JC, Lisboa PC, de Moura EG, Barella LF, Miranda RA, Malta A, Franco CC, Ribeiro TA, Torrezan R, Gravena C, et al. 2013 Poor pubertal protein nutrition disturbs glucose-induced insulin secretion process in pancreatic islets and programs rats in adulthood to increase fat accumulation. Journal of Endocrinology 216 195-206. (https://doi. org/10.1530/JOE-12-0408)

Evuarherhe O, Leggett JD, Waite EJ, Kershaw YM, Atkinson HC \& Lightman SL 2009 Organizational role for pubertal androgens on adult hypothalamic-pituitary-adrenal sensitivity to testosterone in the male rat. Journal of Physiology 587 2977-2985. (https://doi. org/10.1113/jphysiol.2008.168393)

Gomez F \& Dallman MF 2001 Manipulation of androgens causes different energetic responses to cold in 60- and 40-day-old male rats. American Journal of Physiology: Regulatory, Integrative and Comparative Physiology 280 R262-R273. (https://doi.org/10.1152/ ajpregu.2001.280.1.R262)

Grossmann M, Gianatti EJ \& Zajac JD 2010 Testosterone and type 2 diabetes. Current Opinion in Endocrinology, Diabetes and Obesity 17 247-256. (https://doi.org/10.1097/MED.0b013e32833919cf)

Grumbach MM 2002 The neuroendocrinology of human puberty revisited. Hormone Research 57 (Supplement 2) 2-14. (https://doi. org/10.1159/000058094)

Hamilton EJ, Gianatti E, Strauss BJ, Wentworth J, Lim-Joon D, Bolton D, Zajac JD \& Grossmann M 2011 Increase in visceral and subcutaneous abdominal fat in men with prostate cancer treated with androgen deprivation therapy. Clinical Endocrinology 74 377-383. (https://doi. $\operatorname{org} / 10.1111 /$ j.1365-2265.2010.03942.x)

Heiman ML, Ahima RS, Craft LS, Schoner B, Stephens TW \& Flier JS 1997 Leptin inhibition of the hypothalamic-pituitary-adrenal axis in response to stress. Endocrinology 138 3859-3863. (https://doi. org/10.1210/endo.138.9.5366)

Jones TH $2010 a$ Effects of testosterone on Type 2 diabetes and components of the metabolic syndrome. Journal of Diabetes 2 146-156. (https://doi.org/10.1111/j.1753-0407.2010.00085.x)

Jones TH $2010 b$ Testosterone deficiency: a risk factor for cardiovascular disease? Trends in Endocrinology and Metabolism 21 496-503. (https:// doi.org/10.1016/j.tem.2010.03.002)
Kapoor D, Malkin CJ, Channer KS \& Jones TH 2005 Androgens, insulin resistance and vascular disease in men. Clinical Endocrinology 63 239-250. (https://doi.org/10.1111/j.1365-2265.2005.02299.x)

Leon-Quinto T, Magnan C \& Portha B 1998 Altered activity of the autonomous nervous system as a determinant of the impaired beta-cell secretory response after protein-energy restriction in the rat. Endocrinology 139 3382-3389. (https://doi.org/10.1210/ endo.139.8.6149)

Malta A, de Oliveira JC, Ribeiro TA, Tofolo LP, Barella LF, Prates KV, Miranda RA, Elmhiri G, Franco CC, Agostinho AR, et al. 2014 Lowprotein diet in adult male rats has long-term effects on metabolism. Journal of Endocrinology 221 293-303. (https://doi.org/10.1530/JOE13-0473)

Malta A, de Moura EG, Ribeiro TA, Tofolo LP, Abdennebi-Najar L, Vieau D, Barella LF, de Freitas Mathias PC, Lisboa PC \& de Oliveira JC 2016 Protein-energy malnutrition at mid-adulthood does not imprint long-term metabolic consequences in male rats. European Journal of Nutrition 55 1423-1433. (https://doi.org/10.1007/ s00394-015-0960-8)

Marty N, Dallaporta M \& Thorens B 2007 Brain glucose sensing, counterregulation, and energy homeostasis. Physiology 22 241-251. (https://doi.org/10.1152/physiol.00010.2007)

Matsuda M \& DeFronzo RA 1999 Insulin sensitivity indices obtained from oral glucose tolerance testing: comparison with the euglycemic insulin clamp. Diabetes Care 22 1462-1470. (https://doi.org/10.2337/ diacare.22.9.1462)

Mauvais-Jarvis F 2011 Estrogen and androgen receptors: regulators of fuel homeostasis and emerging targets for diabetes and obesity. Trends in Endocrinology and Metabolism 22 24-33. (https://doi.org/10.1016/j. tem.2010.10.002)

McInnes KJ, Smith LB, Hunger NI, Saunders PT, Andrew R \& Walker BR 2012 Deletion of the androgen receptor in adipose tissue in male mice elevates retinol binding protein 4 and reveals independent effects on visceral fat mass and on glucose homeostasis. Diabetes 61 1072-1081. (https://doi.org/10.2337/db11-1136)

Miranda RA, da Silva Franco CC, de Oliveira JC, Barella LF, Tofolo LP, Ribeiro TA, Pavanello A, da Conceicao EP, Torrezan R, Armitage J, et al. 2017 Cross-fostering reduces obesity induced by early exposure to monosodium glutamate in male rats. Endocrine.

Morton GJ, Meek TH, Matsen ME \& Schwartz MW 2015 Evidence against hypothalamic-pituitary-adrenal axis suppression in the antidiabetic action of leptin. Journal of Clinical Investigation 125 4587-4591. (https://doi.org/10.1172/JCI82723)

Noriega NC, Howdeshell KL, Furr J, Lambright CR, Wilson VS \& Gray LE Jr 2009 Pubertal administration of DEHP delays puberty, suppresses testosterone production, and inhibits reproductive tract development in male Sprague-Dawley and Long-Evans rats. Toxicological Sciences 111 163-178. (https://doi.org/10.1093/toxsci/kfp129)

Olamoyegun MA, Oluyombo R \& Asaolu SO 2016 Evaluation of dyslipidemia, lipid ratios, and atherogenic index as cardiovascular risk factors among semi-urban dwellers in Nigeria. Annals of African Medicine 15 194-199. (https://doi.org/10.4103/1596-3519.194280)

Prodam F, Ricotti R, Agarla V, Parlamento S, Genoni G, Balossini C, Walker GE, Aimaretti G, Bona G \& Bellone S 2013 High-end normal adrenocorticotropic hormone and cortisol levels are associated with specific cardiovascular risk factors in pediatric obesity: a crosssectional study. BMC Medicine 11 44. (https://doi.org/10.1186/17417015-11-44)

Ramos CF \& Zamoner A 2014 Thyroid hormone and leptin in the testis. Frontiers in Endocrinology 5 198. (https://doi.org/10.3389/ fendo.2014.00198)

Ravelli AC, van Der Meulen JH, Osmond C, Barker DJ \& Bleker OP 1999 Obesity at the age of $50 \mathrm{y}$ in men and women exposed to famine prenatally. American Journal of Clinical Nutrition 70 811-816. (https:// doi.org/10.1093/ajcn/70.5.811)
() 2018 Society for Endocrinology Published by Bioscientifica Ltd. Printed in Great Britain 
Reeves PG, Nielsen FH \& Fahey GC Jr 1993 AIN-93 purified diets for laboratory rodents: final report of the American Institute of Nutrition ad hoc writing committee on the reformulation of the AIN-76A rodent diet. Journal of Nutrition 123 1939-1951. (https://doi. org/10.1093/jn/123.11.1939)

Retana-Marquez S, Bonilla-Jaime H, Vazquez-Palacios G, MartinezGarcia R \& Velazquez-Moctezuma J 2003 Changes in masculine sexual behavior, corticosterone and testosterone in response to acute and chronic stress in male rats. Hormones and Behavior 44 327-337. (https://doi.org/10.1016/j.yhbeh.2003.04.001)

Reyes-Castro LA, Rodriguez JS, Rodriguez-Gonzalez GL, Chavira R, Bautista CJ, McDonald TJ, Nathanielsz PW \& Zambrano E 2012 Pre- and/or postnatal protein restriction developmentally programs affect and risk assessment behaviors in adult male rats. Behavioural Brain Research 227 324-329. (https://doi.org/10.1016/j. bbr.2011.06.008)

Reynolds RM 2013 Glucocorticoid excess and the developmental origins of disease: two decades of testing the hypothesis - 2012 Curt Richter Award Winner. Psychoneuroendocrinology 38 1-11. (https://doi. org/10.1016/j.psyneuen.2012.08.012)

Reynolds RM, Walker BR, Syddall HE, Andrew R, Wood PJ, Whorwood CB \& Phillips DI 2001 Altered control of cortisol secretion in adult men with low birth weight and cardiovascular risk factors. Journal of Clinical Endocrinology and Metabolism 86 245-250. (https://doi. org/10.1210/jcem.86.1.7145)

Saad F, Yassin A, Doros G \& Haider A 2016 Effects of long-term treatment with testosterone on weight and waist size in 411 hypogonadal men with obesity classes I-III: observational data from two registry studies. International Journal of Obesity 40 162-170. (https://doi.org/10.1038/ ijo.2015.139)

Schwartz MW, Woods SC, Porte D Jr, Seeley RJ \& Baskin DG 2000 Central nervous system control of food intake. Nature $\mathbf{4 0 4} 661-671$. (https:// doi.org/10.1038/35007534)
Scott AM, Atwater I \& Rojas E 1981 A method for the simultaneous measurement of insulin release and B cell membrane potential in single mouse islets of Langerhans. Diabetologia 21 470-475.

Tilbrook AJ, Turner AI \& Clarke IJ 2000 Effects of stress on reproduction in non-rodent mammals: the role of glucocorticoids and sex differences. Reviews of Reproduction 5 105-113. (https://doi. org/10.1530/ror.0.0050105)

Trinder P 1969 Determination of blood glucose using an oxidaseperoxidase system with a non-carcinogenic chromogen. Journal of Clinical Pathology 22 158-161. (https://doi.org/10.1136/jcp.22.2.158)

Uauy R, Kain J \& Corvalan C 2011 How can the Developmental Origins of Health and Disease (DOHaD) hypothesis contribute to improving health in developing countries? American Journal of Clinical Nutrition 94 1759S-1764S. (https://doi.org/10.3945/ajcn.110.000562)

van Abeelen AF, Elias SG, Bossuyt PM, Grobbee DE, van der Schouw YT, Roseboom TJ \& Uiterwaal CS 2012 Famine exposure in the young and the risk of type 2 diabetes in adulthood. Diabetes $612255-2260$. (https://doi.org/10.2337/db11-1559)

Viau V 2002 Functional cross-talk between the hypothalamic-pituitarygonadal and -adrenal axes. Journal of Neuroendocrinology 14 506-513. (https://doi.org/10.1046/j.1365-2826.2002.00798.x)

Vicente LL, de Moura EG, Lisboa PC, Monte Alto Costa A, Amadeu T, Mandarim-de-Lacerda CA \& Passos MC 2004 Malnutrition during lactation in rats is associated with higher expression of leptin receptor in the pituitary of adult offspring. Nutrition 20 924-928. (https://doi. org/10.1016/j.nut.2004.06.014)

Wang M 2005 The role of glucocorticoid action in the pathophysiology of the Metabolic Syndrome. Nutrition and Metabolism 2 3. (https://doi. org/10.1186/1743-7075-2-3)

Woods SC, Seeley RJ \& Cota D 2008 Regulation of food intake through hypothalamic signaling networks involving mTOR. Annual Review of Nutrition 28 295-311. (https://doi.org/10.1146/annurev. nutr.28.061807.155505)

Received in final form 26 February 2018

Accepted 28 March 2018 http://joe.endocrinology-journals.org

https://doi.org/10.1530/JOE-17-0606
() 2018 Society for Endocrinology Published by Bioscientifica Ltd. Printed in Great Britain 